\title{
The editor's dilemma: assessing papers from low-income countries
}

\section{Peter Tyrer FMedSci}

Editor, British Journal of Psychiatry; Department of Psychological Medicine, Imperial College (Charing Cross Campus), London W6 8RP, UK

$\mathrm{M}$ ost scientists are now aware of what has been called the 10:90 divide (Saxena et al, 2006): the fact that $90 \%$ of the published scientific activity in the world comes from the richest $10 \%$ of countries. Many would like to brush off this simple fact as unimportant, but at another level it could be regarded as a scandalous disequilibrium of the planet's resources. One small way of reversing this is for editors to publish more papers from low-income countries and counter what can be described somewhat strongly as editorial racism (Horton, 2003). We have tried to do so in the British Journal of Psychiatry (Tyrer, 2005); this paper describes some of the difficulties.

Seven strategies can be identified in the assessment of papers by authors from low-income countries. Not all of them are ones for which we can burst with pride in exposing, but they need to be discussed.

\section{Seven strategies}

\section{(1) Positive discrimination}

This is a two-edged sword. It allows a sloping playing field to be tilted towards the horizontal but runs the risk of going too far and being unfair to other authors. At its most extreme, it could lead to authors from rich countries who despair of getting any of their work published in good journals recruiting collaborators from low-income ones to improve their political correctness and then get publishing success. So there has to be a balanced form of positive discrimination, one that is seen by all as essentially fair. This is easy to say but difficult to achieve in practice. I will take one example from Ecuador to illustrate this (Incayawar, 2008). Dr Incayawar describes the diagnostic skills of yachactaitas (Quichua healers) in the Andes in relation to mental illness. There was an element of positive discrimination in selecting this paper for publication. Our publication rate from Ecuador was previously nil. The country does not have a well-developed mental health service and it is reasonable to look at the ability of yachactaitas to buttress any other (rich country) models of service, as it may give some interesting insights into the diagnostic process in psychiatry. However, all editors have also to be aware of the main interests of their readers, and I suspect the ability of yachactaitas to diagnose correctly is not especially high on the agendas of most of mine.

\section{(2) Paternalistic rejection}

One of the common problems with papers from low-income countries is what is best described as 'lack of savvy', or reduced ability to identify what should be included in a publication emanating from a rich country. Papers representing this in its most extreme form provoke guffaws and amazement at such naivety and tend to lead to a somewhat patronising response. Although this is couched in language to avoid offence, the response is essentially along the lines of 'It is clear you have no idea of how to write a scientific paper. Your $X, Y$ and $Z$ sections do not conform to journal style, your paper is too long/short, and your references are up the shoot. Go away and come back only when you have learnt how to write a paper properly.' This is a very easy trap to fall into; one of the standard refuges of an editor is to look at the structure without examining the content, and I constantly have to remind myself to do this the other way round.

\section{(3) Capacity building}

This is the counter to patronising paternalism. We should be attempting to build research (and publishing) capacity in low-income countries and giving advice that promotes this is the right response. So, if a paper is rejected but is essentially sound, it is often a good idea to invite a resubmission and spell out in much more detail for this group of authors how this should be achieved. This is where our international representatives on the editorial board can be so helpful, as they can provide local knowledge and advice.

\section{(4) Impact factor}

The impact factor is measured as the ratio of the number of citations of articles appearing in the 2 years following publication in the relevant journal to the total number of articles published in the relevant year. For 2008, for example, this would be the total number of citations of 2006 and 2007 original papers (not editorials) in 2008 divided by the total paper numbers. Thus, the impact factor of 5.45 for the British Journal of Psychiatry in 2007 indicates that the average number of citations in 2007 for each paper published in 2005 and 2006 is just over 5. It is not easy to keep up this level, and the papers published from low-income countries, where journals are few, are much less likely to be cited than papers from rich countries (Patel \& Kim, 2007), another form of imbalance, which could be called citation racism.

The paper by Dr Incayawar (2008) is not likely to be cited as often as many others, as it is unlikely that any local journal will be indexed (i.e. be part of the 'inner group' of journals that are recorded for citation purposes) and so many references to it would go unrecorded.

As journal editors are naturally proud of their impact factors, as badges of intellectual virility and success (Howard \& Wilkinson, 1998), they do not want to have theirs reduced, and so tend to reject many papers from low-income countries. This is a trend that can be countered by journals becoming more genuinely international in their outlook. 


\section{(5) Parochialism}

This, the opposite of internationalism, represents the natural, but wrong, tendency to be partial towards familiar and local research. This creates a bias against low-income countries and can be referred to as the 'Chamberlain effect', named after Neville Chamberlain, the British Prime Minister in 1938, who declined to intervene in Hitler's takeover of Czechoslovakia, on the grounds that 'this is a far-away country of which we know little'. We have to realise that no country on this planet can be regarded as too far away.

\section{(6) English language}

We are remarkably lucky in the UK that English is now the language of international communication. However, it is a fiendishly difficult language in which to write good scientific papers, and many authors from low-income countries whose main language is not English know this to their peril. It is therefore extremely easy to reject a paper that might otherwise be important on the grounds that it reads badly. Of course, if it is badly written it will not convey the authors message, but it is right and proper to make some allowance for this in assessing contributions from those who do not have an English ghost writer waiting constantly by their side.

\section{(7) Laziness}

This is left to the end because it is linked to all the previous six points. An editor usually has to work harder with authors from low-income countries than with those from richer ones in order to get their papers to the printed page. If laziness intervenes, it is much easier to press the reject button than to put in the extra effort required. It is always possible to get an editor on a bad day, when the level of work is overwhelming, and under these circumstances the author from a low-income country is at a distinct disadvantage. My advice is to persist despite adversity.

\section{References}

Horton, R. (2003) Medical journals: evidence of bias against the diseases of poverty. Lancet, 361, 712-713.

Howard, L. \& Wilkinson, G. (1998) Impact factors of psychiatric journals. The British Journal of Psychiatry now has the highest impact factor of all psychiatric journals outside the USA. British Journal of Psychiatry, 172,457

Incayawar, M. (2008) Efficacy of Quichua healers as psychiatric diagnosticians. British Journal of Psychiatry, 192, 390-391.

Patel, V. \& Kim, Y-R. (2007) Contribution of low- and middle-income countries to research published in leading general psychiatry journals, 2002-2004. British Journal of Psychiatry, 190, 77-78.

Saxena, S., Paraje, G., Sharan, P., et al (2006) The 10/90 divide in mental health research: trends over a 10-year period. British Journal of Psychiatry, 188, 81-82.

Tyrer, P. (2005) Combating editorial racism in psychiatric publications. British Journal of Psychiatry, 186, 1-3.

\section{Child and adolescent psychiatry services in low- and middle-income countries}

\section{David Skuse}

Behavioural and Brain Sciences Unit, Institute of Child Health, London WC1N 1EH, UK, email dskuse@ich.ucl.ac.uk

$T^{\text {the }}$ he theme in this issue concerns the interface between child psychiatric services in low- and middle-income countries and the availability of such services in higherincome countries. In neither context are such services ideal, and resources are relatively slim when compared with demand. The key issues are discussed in three terms: first, of the need for nations to have a general statement of child and adolescent mental health policy (Shatkin et al); second, of the need to establish international child and mental health research networks to foster research in lowand middle-income countries (Erlich \& Plener); and third, of the circumstances that exist for providing such support to children in one such country, Pakistan (Khan et al).

The major concern of all three sets of contributors is that there are very few countries with policies that address the mental health needs of this client group. Since the Convention on the Rights of the Child was implemented in 1989 by the United Nations, children have had, on paper at least, the opportunity to seek mental health support in all 193 countries that have ratified the agreement. There is a serious lack of resources in many of these countries. We know from international efforts to investigate the prevalence of mental health problems that they will affect up to one in five children, irrespective of culture. Shatkin et al reviewed the provision of services in all participating countries and found that only 35 had any sort of mental health policy for children, and of these only a minority provided good-quality and flexible care. In all cases, child and adolescent psychiatry was subject to the same range of policies as adult psychiatric services, however inappropriate that might be in objective terms. Clearly, the Atlas project, in which they attempted to gain an overview of child mental health provision around the world, is of potentially great value and significance, but it failed to gain adequate relevant information from many countries because there was no statutory authority tasked with collecting or providing it.

There is a need for more epidemiological information about the range and nature of child mental health problems in low- and middle-income countries, and in order to gain such knowledge we need to have more appropriate trained researchers in child psychiatry where those studies are needed. Stefan Ehrlich and Paul Plener describe how they are 